\title{
Primary Care Physicians' Knowledge of and Experience with Pharmacogenetic Testing
}

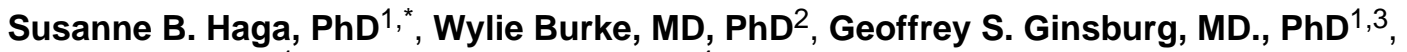 \\ Rachel Mills, $\mathbf{M S}^{1}$, and Robert Agans, PhD $^{4}$ \\ ${ }^{1}$ Institute for Genome Sciences \& Policy, Duke University, Durham, NC 27708 \\ 2Department of Bioethics and Humanities, University of Washington, Box 357120, 1959 NE \\ Pacific, Room A204, Seattle, WA 98195 \\ ${ }^{3}$ Department of Medicine, Duke University School of Medicine, Durham, NC 27708 \\ ${ }^{4}$ University of North Carolina, Chapel Hill, Survey Research Unit, 730 Martin Luther King Jr Blvd, \\ Chapel Hill, NC 27514
}

\begin{abstract}
It is anticipated that as the range of drugs for which pharmacogenetic testing becomes available expands, primary care physicians (PCPs) will become major users of these tests. To assess their training, familiarity, and attitudes toward pharmacogenetic testing in order to identify barriers to uptake that may be addressed at this early stage of test use, we conducted a national survey of a sample of PCPs. Respondents were mostly white (79\%), based primarily in community-based primary care $(81 \%)$ and almost evenly divided between family medicine and internal medicine. The majority of respondents had heard of PGx testing and anticipated that these tests are or would soon become a valuable tool to inform drug response. However, only a minority of respondents (13\%) indicated they felt comfortable ordering PGx tests and almost a quarter reported not having any education about pharmacogenetics.
\end{abstract}

CONCLUSIONS-Our results indicate that primary care practitioners envision a major role for themselves in the delivery of PGx testing but recognize their lack of adequate knowledge and experience about these tests. Development of effective tools for guiding PCPs in the use of PGx tests should be a high priority.

\section{INTRODUCTION}

Genetic variation has been estimated to account for 20 to $95 \%$ of the variation in individual responses to medications (1) and many different gene variants have been identified that influence medication response. These findings provide the basis for pharmacogenetic (PGx) testing, the use of genetic tests to determine the optimal pharmaceutical therapy for a given individual patient. This testing approach is considered to be one of the most promising early clinical applications arising from genomics research, with the potential to reduce adverse drug responses and improve drug efficacy. Drug safety is a particularly important target for PGx testing since adverse drug reactions are responsible for about $7 \%$ of all hospital admissions and substantially higher proportion for elderly patients (2-5).

*Corresponding Author, Susanne B. Haga, PhD, Institute for Genome Sciences \& Policy, Duke University, 304 Research Drive, Box 90141, Durham, NC 27708, Tel: 919.684.0325, Fax: 919.613.6448, susanne.haga@ duke.edu.

Conflict of Interests: S.B.H. is a member of the Patient Advisory and Public Policy Board of Generations Health, Inc. No other conflicts of interest are to be declared. 
The routine use of PGx testing has been slow due to several reasons including lack of knowledge and guidelines, little evidence of clinical utility and cost-effectiveness of the test, delay of treatment, availability of alternative treatments, discrimination and ethical concerns (6-12). Several studies have documented physicians' limited knowledge of genetics, genetic testing, and personalized medicine (13-15) including PGx testing (16-21). Despite physicians' limited knowledge, they have expressed interest in using new technologies to improve therapeutic decision-making $(19,22,23)$ though do not appear to be actively preparing for the use of these tests. In contrast, clinical geneticists and pharmacists have both begun to address issues related to the use of PGx testing, including assessing educational needs (24-27), developing educational programs (28-30), defining roles $(25,31$, $32)$, and developing guidelines $(33,34)$ and delivery systems $(35-39)$.

Although PGx tests may be ordered by physicians across a range of medical specialties, primary care physicians (PCPs) will be a major source of information for patients and will potentially utilize a number of PGx tests, given the broad range of conditions they routinely treat. About one-fourth of outpatients are estimated to be taking medications that contain PGx information in their labels, most prescribed by PCPs $(40,41)$. Therefore, we sought their views on their willingness and readiness to utilize PGx testing, desirable test properties, and factors relevant to the use of PGx tests.

\section{METHODS}

\section{Survey Development}

The survey was developed through a collaborative effort between investigators at Duke University's Institute for Genome Sciences \& Policy and the Survey Research Unit at the University of North Carolina, Chapel Hill. The survey questions were based on a literature review and focus groups study of health professionals (18).

\section{Survey Pre-testing}

To evaluate understandability and the ability of respondents to complete the questions as intended, a panel of primary care practitioners pre-tested the survey by completing an online survey evaluation noting confusing questions and ambiguous terms and reporting confidence in answering questions accurately. The resulting survey was comprised of six major parts, totaling 101 questions (see Supplemental Materials). In this paper, we report findings from the first five sections of the survey.

\section{Sampling methods}

The sample was obtained from the American Medical Association (AMA) Physician Masterfile through Direct Medical Data, LLC (Des Plaines, IL). A random sample of physicians meeting the following criteria was requested: 1) board-certified in either Family Medicine or Internal Medicine but not board-certified in a sub-specialty; 2) hold a license to practice in their state of residence; and 3) graduated between 1970 and 2003, thus excluding physicians who are likely to be over the age of 65 and retired. A total of 4,000 names $(2,000$ per frame) were randomly selected from the community of internists $(n=47,348)$ and family medicine practitioners $(\mathrm{n}=47,179)$. The samples were stratified by census regions to ensure representation from the midwest, northeast, south and west.

\section{Data Collection}

To guarantee that the frame data received from the vendor was correct, the SRU screened each case by telephone to verify physician name, mailing address, and eligibility status. In addition to the sample criteria, physicians also needed to be practicing and actively seeing patients to be eligible to complete the survey. Out of the 4,000 physicians sampled, 829 
could not be screened because contact information provided by the vendor was inaccurate and correct information could not be found, 70 cases were ineligible, and 56 cases directly refused participation. The initial round of screening achieved a contact rate of $76 \%$ (3045/4000).

The survey was conducted from November 19, 2010 to April 15, 2011. The mode of data collection included a mailed survey invitation and questionnaire along with a letter of support from the President of the American Academy of Family Physicians (L.Heim) or the past President of the Society of General Internal Medicine (E. Rich) with a postage-paid return envelope. Non-respondents were followed up via telephone, fax, and mailings. The study was approved by the Institutional Review Boards at Duke University Medical Center and the University of North Carolina, Chapel Hill. Respondents who completed the survey were provided $\$ 35$.

Of 3,045 confirmed names/addresses, 597 completed the survey, three were determined to be ineligible, and 2,445 did not respond, yielding a cooperation rate of $20 \%$ (597/3042). The response rate, $15 \%$, was determined by multiplying the contact rate by the cooperation rate $(76 \% \cdot 20 \%)$.

\section{Data Analysis}

Sample weights were produced as the inverse of stratum-specific sampling rates and then adjusted for differential nonresponse per stratum to improve nationwide coverage. Final weights were post-stratified on population counts as provided by the AMA Physician Masterfile based on specialty (internal vs. family medicine), gender (male vs. female), and year of graduation from medical school ( $1980,1981-1990,1991-2000,2001)$. Estimates were weighted and a $95 \%$ confidence bound is provided where applicable. Cochran-MantelHaenszel (CMH) Chi-square tests were conducted, adjusting for gender and race when comparing the two groups (family and internal medicine) on a binary response. All analyses were conducted in SAS (Version 9.2, 2008; SAS Institute Inc., Cary, NC).

\section{RESULTS}

\section{Characteristics of Respondents}

Sample demographics closely mirrored population characteristics with regard to physician gender and year of graduation (Table 1). The only discrepancy with the AMA Physician Masterfile was specialty, with physicians in family medicine responding more frequently than internists. Post-stratification aligned specialty to the population counts, but no other adjustments were possible because ancillary data were not available on the AMA Physician Masterfile. Therefore, meaningful comparisons between respondents and non-respondents could not be made on other demographic characteristics, such as race.

\section{Perceived Knowledge \& Experience with Genetic Testing}

We first asked respondents about their experience with genetic testing in general. When asked if they felt well-informed about genetic testing, 51.4\% (+/-2.25\%) strongly or somewhat disagreed. There was no significant relationship between year of graduation and feeling well-informed ( $\mathrm{p}=.195)$, but physicians board-certified in Family Medicine were less likely to indicate feeling well-informed about genetic testing than internists $(\mathrm{p}=0.022)$. More than half of respondents indicated that they received genetics training in medical school $(57.2+/-2.29 \%)$. Recent graduates were more likely to have indicated that they received genetics training in medical school $(\mathrm{p}<0.0001)$. Most respondents $(73.0 \%+/-2.01 \%)$ indicated that they did not feel their genetics training adequately prepared them to appropriately order or use genetic tests. 
Respondents reported ordering genetic testing for disease susceptibility or diagnosis 1-2 times per year $(38.2+/-2.23 \%)$ or $3-10$ times/year $(30.2 \%+/-2.11 \%)$. Thirty-two percent $(+/-2.15 \%)$ indicated they have never ordered any genetic testing. When asked if they felt comfortable ordering a genetic test to diagnose a disease, $45.7 \%(+/-2.24 \%)$ strongly or somewhat agreed and $38.7 \%(+/-2.18 \%)$ strongly or somewhat disagreed. When asked if they felt comfortable ordering a test to predict disease susceptibility, $38.8 \%(+/-2.19 \%)$ strongly or somewhat agreed and $43.7 \%(+/-2.22 \%)$ strongly or somewhat disagreed. No associations were observed between frequency of test ordering and year of graduation or medical specialty.

\section{PGx Testing}

Most respondents $(72.7+/-1.99 \%)$ reported having heard of PGx testing prior to taking the survey. Twenty-two percent $(+/-1.77 \%)$ reported not having had any form of education about pharmacogenetics. Respondents board-certified in Family Medicine were more likely to have had no education about pharmacogenetics compared to those board-certified in Internal Medicine (27.9\% vs. $17.0 \%)(\mathrm{p}=0.003)$. Sixteen percent $(+/-1.63 \%)$ indicated learning of pharmacogenetics in medical school or through their residency. Most respondents indicated learning about pharmacogenetics through journals $(46.9 \%+/-2.30 \%)$ or professional meetings, CME, or grand rounds $(46.61 \%(+/-2.24 \%) \%)$. Respondents felt that CME (in-person courses) or grand rounds were the best way to educate physicians about PGx testing $(36.5+/-2.23 \%)$, followed by training in residency $(15.5 \%+/-1.67 \%)$. Most respondents (76.2+/- $2.01 \%$ ) were unaware that the Food and Drug Administration had revised drug labels to include pharmacogenetic information.

Twenty percent $(+/-1.87 \%)$ indicated that they have ordered a PGx test at least once a year; $79.6 \%(+/-1.92 \%)$ indicated they had never ordered a PGx test. Most respondents agreed that PGx testing is or will soon be a valuable tool to predict risk of adverse events or likelihood of effectiveness $(64.5+/-2.21 \%$ responded strongly agree or somewhat agree). Only $13 \%(+/-1.67 \%)$ of respondents felt well-informed about the role of PGx testing in therapeutic decision-making and $67 \%(+/-2.20 \%)$ strongly or somewhat disagreed with the statement that they were comfortable ordering a PGx test. Family medicine physicians were less likely to have ordered a PGx test than internists $(\mathrm{p}=0.006)$. Thirty-six percent $(+/$ $-2.06 \%$ ) of respondents indicated they would be more likely to order a comparable nongenetic PGx test (e.g., an enzyme or protein assay) if one was available.

When deciding whether or not to order a PGx test to predict likelihood of an adverse response or determine likelihood of drug efficacy, the severity of the potential drug reaction or the severity of the condition being treated, respectively, was considered the most important factor, followed by the predictive value of the test, and the cost of the test (Table 2). Inclusion of pharmacogenetic information on the drug label and the test turnaround time were considered very important by the smallest proportion of respondents.

\section{Role of PCPs}

We asked respondents to indicate which health professional or group should have primary responsibilities for delivery of different components of PGx testing (Table 3). Overall, most respondents $(62.9+/-2.35 \%)$ believed that they should have primary responsibility for making patients aware of a PGx test for a drug prescribed for them and for determining how the PGx result should be recorded in the medical record $(60.1+/-2.44 \%)$. There was little recognition of other groups (with the exception of disease specialists) in the delivery of PGx testing. They believed that a disease specialist or genetics professional should have primary responsibility for determining which PGx variants should be included in the testing panel $(24.9+/-2.10 \%$ and $33.4+/-2.30 \%$, respectively). Most respondents believed it was their 
responsibility as a primary care provider to discuss PGx test results with the patient $(57.5+/-$ $2.32 \%)$, but the majority of respondents strongly or somewhat agreed $(91.6+/-1.23 \%)$ that they would refer a patient to a genetic specialist for information about familial implications. Respondents also believed it was their responsibility to maintain a record of the patient's PGx test results (76.9+/-2.00\%), and determine how PGx results will affect drug selection $(45.6+/-2.36 \%)$. Ten percent of respondents indicated that pharmacists should have primary responsibility in determining the appropriate dose or drug selection based on the PGx test result. Few significant differences in opinion existed between respondents board-certified in internal medicine compared to family medicine.

\section{DISCUSSION}

Although PGx testing has primarily been used by clinical specialists, it is anticipated that as the number of drugs increases for which testing becomes available, PCPs will become major users of these tests. Therefore, we sought to understand PCPs' training, familiarity, and attitudes toward PGx testing in order to identify barriers to uptake that may be addressed at this early stage of test use. We find that the primary barrier for use is PCPs' lack of education about PGx testing.

Supporting other findings demonstrating the low level of knowledge about pharmacogenetics of physicians $(16,21,23,42)$ and other health professionals (43), most respondents did not feel well-informed about PGx testing nor comfortable ordering PGx testing. Almost a quarter reported not having any education about pharmacogenetics. Herein lies the circularity of our and others findings: until PCPs understand how to determine which tests should be used, what the test results mean and what actions they can take in response, they will remain uncomfortable using PGx tests. Given the rapid developments in pharmacogenetics, traditional educational approaches will likely need to be supplemented by point-of-care assistance such as electronic clinical decisional supports. Although inclusion of PGx information in the drug label was not considered a major factor by respondents in deciding whether they would order a PGx test, more efficient delivery of drug label changes, perhaps linked to e-prescribing databases, would improve awareness of label revisions and use of PGx testing.

Despite the lower than anticipated use of PGx testing in general care practices (44), most respondents' considered PGx testing to be of value and envisioned a major role for PCPs regarding patient education, delivery, and communication of test results. Respondents did not recognize (or in a very limited capacity) a role for other health professionals, particularly pharmacists and clinical geneticists, in the delivery of PGx testing. Given these two groups' involvement in clinical research and test development, one may presume that these two specialties would have a key role in the delivery of PGx testing as well. Indeed, both groups have been addressing issues regarding the clinical use of PGx testing much more actively than PCPs. During this early stage of test use, a partnership with geneticists and/or pharmacists may be of great value to PCPs and mutually beneficial to all. PCPs should be able to determine when testing is appropriate on their own, but collaborate with the clinical geneticist and/or pharmacist regarding interpretation and application of results. Although collaboration between PCPs and pharmacists has been demonstrated to improve outcomes $(45,46)$, fostering these relationships has been challenging for some, which may account for the limited recognition of this group. Pharmacy benefit managers in the U.S. have begun to provide PGx testing to covered patients for select medications (47). We and other groups are currently exploring the use of pharmacist-assisted delivery of PGx testing in the primary care setting. If preemptive PGx testing and clinical decision alerts become widespread, PCPs themselves may actually have a limited role (48). Analogous to the dual certification 
program in pathology and clinical genetics, a new combined specialty could be created linking pharmacology and clinical genetics.

Some of our data substantially differ from a recent survey of U.S. physicians by Stanek et al. (21). Stanek et al. reported that almost 30\% of respondents received training about PGx testing in medical school or post-graduate training, compared to $16 \%$ of our respondents. Whereas almost $40 \%$ of respondents in their survey indicated learning about pharmacogenetics from drug labels (21), 76\% of our respondents indicated they were unaware of drug label revisions including PGx information. With respect to test use, we show a lower test use (ever) than reported by Stanek et al. (11.7\% of internists and family medicine physicians reported ordering a PGx test in last 6 months). These disparate findings may be attributed to differences in the study population: Stanek et al. 's population included specialists, was drawn from the Medco physician database, and differences in physician age. Furthermore, the 2-year time difference between when the surveys were conducted ( 2008 vs. 2010) could account for differences given the rapid pace of development in pharmacogenetics.

Physician knowledge is but one factor influencing uptake of testing and in some cases, may not be the major factor driving use of PGx testing. In addition to lack of knowledge, several other factors may contribute to the low use of PGx tests, such as concern about communicating complex test results, reimbursement, and lack of clinical guidelines $(20,49)$. We found that the severity of the adverse response or condition being treated was considered the most important factor in deciding whether to order a PGx test to predict drug response, comporting with previous findings about perceived benefit to reduce adverse responses (32, 42). In contrast to another published study, turnaround time was not rated as highly compared to other factors (50). Similar to other findings (20), a third of respondents indicated they would be more likely to order a non-genetic PGx tests, perhaps due to a combination of perceived patient concerns and physician unfamiliarity or lack of comfort with DNA-based testing.

There were some differences between respondents board-certified in family medicine and internal medicine. In particular, family medicine physicians were significantly more likely to have had no education about pharmacogenetics and less likely to have ordered a PGx test compared to internists. Substantially differing rates of use of PGx testing associated with azathioprine have been reported, speculated to be due to different national guidelines about test use(51). The higher knowledge and experience of internists compared to family medicine physicians may be attributed to an older patient population with correspondingly higher rate of drug prescription.

Some limitations of our study should be noted, specifically the low response rate. Although respondents' views on PGx testing may differ from PCPs as a whole due to selection bias, their lack of confidence regarding the use of PGx and low genetic knowledge is consistent with other data. Even if their positive expectations about the value of PGx testing represent a minority view, our data also indicate a significant reservoir of potential early adopters.

Further study will be needed to validate our findings and determine the most appropriate and effective methods for guidance and education.

In conclusion, our results indicate that PCPs envision a major role for themselves in the delivery of PGx testing but recognize their lack of adequate knowledge and experience. As the most recent survey to date, our findings suggest that educational curricula, training and resources have not significantly advanced, have not reached or are being utilized by PCPs, or are not effective in promoting comfort about PGx testing. Therefore, development of effective tools for guiding PCPs in the use of PGx tests should be a high priority. In addition 
to traditional formal education in medical school and residency curricula, clinical decisional supports and professional partnerships may be the most effective and flexible tools to educate physicians about the use of PGx testing.

\section{Supplementary Material}

Refer to Web version on PubMed Central for supplementary material.

\section{Acknowledgments}

This work was supported by the National Institutes of Health (R01 GM081416-01A1).

\section{References}

1. Evans WE, McLeod HL. Pharmacogenomics--drug disposition, drug targets, and side effects. The New England journal of medicine. 2003; 348:538-549. [PubMed: 12571262]

2. Lazarou J, Pomeranz BH, Corey PN. Incidence of adverse drug reactions in hospitalized patients: a meta-analysis of prospective studies. JAMA : the journal of the American Medical Association. 1998; 279:1200-1205. [PubMed: 9555760]

3. Patel H, Bell D, Molokhia M, et al. Trends in hospital admissions for adverse drug reactions in England: analysis of national hospital episode statistics 1998-2005. BMC clinical pharmacology. 2007; 7:9. [PubMed: 17894876]

4. Pirmohamed M, James S, Meakin S, et al. Adverse drug reactions as cause of admission to hospital: prospective analysis of 18820 patients. Bmj. 2004; 329:15-19. [PubMed: 15231615]

5. van der Hooft CS, Sturkenboom MC, van Grootheest K, et al. Adverse drug reaction-related hospitalisations: a nationwide study in The Netherlands. Drug safety : an international journal of medical toxicology and drug experience. 2006; 29:161-168. [PubMed: 16454543]

6. Corkindale D, Ward H, McKinnon R. Low adoption of pharmacogenetic testing: an exploration and explanation of the reasons in Australia. Pers Med. 2007; 4:191-199.

7. McKinnon RA, Ward MB, Sorich MJ. A critical analysis of barriers to the clinical implementation of pharmacogenomics. Therapeutics and clinical risk management. 2007; 3:751-759. [PubMed: 18473000]

8. Schnoll RA, Shields AE. Physician barriers to incorporating pharmacogenetic treatment strategies for nicotine dependence into clinical practice. Clinical pharmacology and therapeutics. 2011; 89:345-347. [PubMed: 21326262]

9. Shah J. Criteria influencing the clinical uptake of pharmacogenomic strategies. Bmj. 2004; 328:1482-1486. [PubMed: 15205293]

10. Webster A, Martin P, Lewis G, et al. Integrating pharmacogenetics into society: in search of a model. Nature reviews Genetics. 2004; 5:663-669.

11. Haddy CA, Ward HM, Angley MT, et al. Consumers' views of pharmacogenetics--A qualitative study. Res Social Adm Pharm. 2010; 6:221-231. [PubMed: 20813335]

12. Zgheib NK, Arawi T, Mahfouz RA, et al. Attitudes of health care professionals toward pharmacogenetic testing. Molecular diagnosis \& therapy. 2011; 15:115-122. [PubMed: 21623646]

13. Hofman KJ, Tambor ES, Chase GA, et al. Physicians' knowledge of genetics and genetic tests. Academic medicine : journal of the Association of American Medical Colleges. 1993; 68:625632. [PubMed: 8352875]

14. Hunter A, Wright P, Cappelli M, et al. Physician knowledge and attitudes towards molecular genetic (DNA) testing of their patients. Clinical genetics. 1998; 53:447-455. [PubMed: 9712533]

15. Wideroff L, Vadaparampil ST, Greene MH, et al. Hereditary breast/ovarian and colorectal cancer genetics knowledge in a national sample of US physicians. Journal of medical genetics. 2005; 42:749-755. [PubMed: 15784723]

16. Dodson C. Analysis of clinicians' attitudes towards pharmacogenomics. Pers Med. 2011; 8:8. 
17. Fargher EA, Eddy C, Newman W, et al. Patients' and healthcare professionals' views on pharmacogenetic testing and its future delivery in the NHS. Pharmacogenomics. 2007; 8:15111519. [PubMed: 18034616]

18. Haga SB, Tindall G, O'Daniel JM. Professional Perspectives About Pharmacogenetic Testing and Managing Ancillary Findings. Genetic testing and molecular biomarkers. 2011

19. Shields AE, Blumenthal D, Weiss KB, et al. Barriers to translating emerging genetic research on smoking into clinical practice. Perspectives of primary care physicians. Journal of general internal medicine. 2005; 20:131-138. [PubMed: 15836545]

20. Shields AE, Levy DE, Blumenthal D, et al. Primary care physicians' willingness to offer a new genetic test to tailor smoking treatment, according to test characteristics. Nicotine \& tobacco research : official journal of the Society for Research on Nicotine and Tobacco. 2008; 10:10371045.

21. Stanek EJ, Sanders CL, Taber KA, et al. Adoption of pharmacogenomic testing by US physicians: results of a nationwide survey. Clinical pharmacology and therapeutics. 2012; 91:450-458. [PubMed: 22278335]

22. Grant RW, Hivert M, Pandiscio JC, et al. The clinical application of genetic testing in type 2 diabetes: a patient and physician survey. Diabetologia. 2009; 52:2299-2305. [PubMed: 19727660]

23. Dodson C. Knowledge and attitudes concerning pharmacogenomics among healthcare. Pers Med. 2011; 8:8.

24. AACP. Final Report of the 2007-2008 Bylaws and Policy Development Committee. American journal of pharmaceutical education. 2008:72.

25. Brock TP, Faulkner CM, Williams DM, et al. Continuing-education programs in pharmacogenomics for pharmacists. Am J Health-Syst Ph. 2002; 59:722-725.

26. Murphy JE, Green JS, Adams LA, et al. Pharmacogenomics in the curricula of colleges and schools of pharmacy in the United States. American journal of pharmaceutical education. 2010; 74:7. [PubMed: 20221358]

27. Thomas RA, Voytilla R, Knutson AR. APhA2010 House of Delegates: Paving the way for the profession's best practices. J Am Pharm Assoc. 2010; 50:450-458.

28. Springer JA, Iannotti NV, Kane MD, et al. Pharmacogenomics training using an instructional software system. American journal of pharmaceutical education. 2011; 75:32. [PubMed: 21519421]

29. Zembles T. An inservice program on pharmacogenetics to individualize drug therapy. American journal of pharmaceutical education. 2010; 74:10. [PubMed: 20221361]

30. Genetics ACoM. Medical Genetics: Translating Genes Into Health. 2012; Vol.

31. Clemerson JP, Payne K, Bissell P, et al. Pharmacogenetics, the next challenge for pharmacy? Pharmacy world \& science : PWS. 2006; 28:126-130.

32. El-Ibiary SY, Cheng C, Alldredge B. Potential roles for pharmacists in pharmacogenetics. Journal of the American Pharmacists Association : JAPhA. 2008; 48:e21-e29. quiz e30-32. [PubMed: 18359724]

33. Swen JJ, Nijenhuis M, de Boer A, et al. Pharmacogenetics: from bench to byte--an update of guidelines. Clinical pharmacology and therapeutics. 2011; 89:662-673. [PubMed: 21412232]

34. Flockhart DA, O'Kane D, Williams MS, et al. Pharmacogenetic testing of CYP2C9 and VKORC1 alleles for warfarin. Genetics in medicine : official journal of the American College of Medical Genetics. 2008; 10:139-150. [PubMed: 18281922]

35. Allison M. US pharmacies broaden access to pharmacogenetic tests. Nature biotechnology. 2010; 28:299-300.

36. Padgett L, O'Connor S, Roederer M, et al. Pharmacogenomics in a community pharmacy: ACT now. Journal of the American Pharmacists Association : JAPhA. 2011; 51:189-193. [PubMed: 21382809]

37. Swen JJ, van der Straaten T, Wessels JA, et al. Feasibility of pharmacy-initiated pharmacogenetic screening for CYP2D6 and CYP2C19. European journal of clinical pharmacology. 2012; 68:363370. [PubMed: 21984116]

38. Crews KR, Cross SJ, McCormick JN, et al. Development and implementation of a pharmacistmanaged clinical pharmacogenetics service. American journal of health-system pharmacy : AJHP : 
official journal of the American Society of Health-System Pharmacists. 2011; 68:143-150. [PubMed: 21200062]

39. Reiss SM. Integrating pharmacogenomics into pharmacy practice via medication therapy management. Journal of the American Pharmacists Association : JAPhA. 2011; 51:e64-e74. [PubMed: 22001957]

40. Frueh FW, Amur S, Mummaneni P, et al. Pharmacogenomic biomarker information in drug labels approved by the United States food and drug administration: prevalence of related drug use. Pharmacotherapy. 2008; 28:992-998. [PubMed: 18657016]

41. Grice GR, Seaton TL, Woodland AM, et al. Defining the opportunity for pharmacogenetic intervention in primary care. Pharmacogenomics. 2006; 7:61-65. [PubMed: 16354125]

42. Tamaoki M, Gushima H, Tsutani K. Awareness survey of parties involved in pharmacogenomics in Japan. Pharmacogenomics. 2007; 8:275-286. [PubMed: 17324116]

43. McCullough KB, Formea CM, Berg KD, et al. Assessment of the pharmacogenomics educational needs of pharmacists. American journal of pharmaceutical education. 2011; 75:51. [PubMed: 21655405]

44. Swen JJ, Guchelaar HJ. Just how feasible is pharmacogenetic testing in the primary healthcare setting? Pharmacogenomics. 2012; 13:507-509. [PubMed: 22462740]

45. Padiyara RS, D'Souza JJ, Rihani RS. Clinical Pharmacist Intervention and the Proportion of Diabetes Patients Attaining Prevention Objectives in a Multispecialty Medical Group. J Manage Care Pharm. 2011; 17:456-462.

46. Pape GA, Hunt JS, Butler KL, et al. Team-based care approach to cholesterol management in diabetes mellitus: two-year cluster randomized controlled trial. Archives of internal medicine. 2011; 171:1480-1486. [PubMed: 21911633]

47. Topol EJ. Pharmacy benefit managers, pharmacies, and pharmacogenomic testing: prescription for progress? Science translational medicine. 2010; $244 \mathrm{~cm} 22$.

48. Dolgin E. Preemptive genotyping trialed to prevent adverse drug reactions. Nature medicine. 2011; 17:1323.

49. Kadafour M, Haugh R, Posin M, et al. Survey on warfarin pharmacogenetic testing among anticoagulation providers. Pharmacogenomics. 2009; 10:1853-1860. [PubMed: 19891559]

50. Payne K, Fargher EA, Roberts SA, et al. Valuing pharmacogenetic testing services: a comparison of patients' and health care professionals' preferences. Value in health : the journal of the International Society for Pharmacoeconomics and Outcomes Research. 2011; 14:121-134. [PubMed: 21211494]

51. Fargher EA, Tricker K, Newman W, et al. Current use of pharmacogenetic testing: a national survey of thiopurine methyltransferase testing prior to azathioprine prescription. Journal of clinical pharmacy and therapeutics. 2007; 32:187-195. [PubMed: 17381669] 
Table 1

Characteristics of Survey Respondents $(n=597)$.

\begin{tabular}{|c|c|c|}
\hline Characteristic & $\begin{array}{c}\text { Total } \\
\text { Respondents } \\
\text { (Unweighted \%) }\end{array}$ & $\begin{array}{c}\text { Total } \\
\text { Respondents } \\
(\text { Weighted \%) }\end{array}$ \\
\hline Male & 63.99 & 65.96 \\
\hline \multicolumn{3}{|l|}{ Race* } \\
\hline - White & 78.11 & 74.78 \\
\hline - African-American & 2.19 & 2.09 \\
\hline - Asian & 14.14 & 17.45 \\
\hline - Other/Prefer Not to Answer & 5.56 & 5.68 \\
\hline Hispanic & 3.72 & 3.59 \\
\hline \multicolumn{3}{|l|}{ Year of Medical School Graduation } \\
\hline - 1980 or before & 19.43 & 18.07 \\
\hline - 1981-1990 & 38.36 & 38.04 \\
\hline - 1991-2000 & 34.00 & 36.36 \\
\hline - After 2000 & 8.21 & 7.53 \\
\hline \multicolumn{3}{|l|}{ Medical Specialty* } \\
\hline - Family Medicine & 61.08 & 40.58 \\
\hline - Internal Medicine & 37.90 & 58.21 \\
\hline - Other & 1.02 & 1.21 \\
\hline \multicolumn{3}{|l|}{ Practice Environment } \\
\hline Community-based & 82.23 & 79.17 \\
\hline Hospital based & 10.863 & 14.12 \\
\hline Other & 6.94 & 6.71 \\
\hline
\end{tabular}


Table 2

Comparison of perceived importance of characteristics of PGx testing to predict likelihood of adverse response or drug efficacy (percentage).

\begin{tabular}{|c|c|c|c|c|}
\hline \multirow[t]{2}{*}{ Test Characteristic } & \multicolumn{2}{|c|}{$\begin{array}{l}\text { PGx testing to predict } \\
\text { likelihood of adverse } \\
\text { response } 1\end{array}$} & \multicolumn{2}{|c|}{$\begin{array}{c}\text { PGx testing to predict } \\
\text { likelihood of drug } \\
\text { efficacy }^{2}\end{array}$} \\
\hline & $\begin{array}{l}\text { Very } \\
\text { important }\end{array}$ & $\begin{array}{l}\text { Somewhat } \\
\text { important }\end{array}$ & $\begin{array}{l}\text { Very } \\
\text { important }\end{array}$ & $\begin{array}{l}\text { Somewhat } \\
\text { important }\end{array}$ \\
\hline Severity of potential drug reaction & 0.78 & 0.16 & -- & -- \\
\hline Prevalence of the potential reaction & 0.50 & 0.41 & -- & -- \\
\hline Likelihood of non-response & -- & -- & 0.48 & 0.41 \\
\hline Predictive value of the test & 0.58 & 0.31 & 0.57 & 0.32 \\
\hline Availability of other clinical testing to monitor drug toxicity (or drug response) & 0.34 & 0.49 & 0.38 & 0.48 \\
\hline Severity of the condition being treated & 0.49 & 0.37 & 0.58 & 0.33 \\
\hline Urgency of treatment & -- & -- & 0.43 & 0.39 \\
\hline Prevalence of the genetic variant & 0.37 & 0.43 & 0.34 & 0.51 \\
\hline Inclusion of information about the test on the drug label & 0.18 & 0.32 & 0.19 & 0.33 \\
\hline Availability of practice guidelines & 0.49 & 0.37 & 0.49 & 0.36 \\
\hline Insurance reimbursement of test & 0.51 & 0.27 & 0.48 & 0.30 \\
\hline Cost of the test & 0.56 & 0.29 & 0.52 & 0.33 \\
\hline Turnaround time for the test results & 0.21 & 0.41 & 0.22 & 0.42 \\
\hline Cost of the drug for which the test is ordered & 0.23 & 0.42 & 0.31 & 0.41 \\
\hline Availability of alternative drug & .39 & .46 & 0.36 & 0.48 \\
\hline
\end{tabular}

1 Survey Question: "In your opinion, when deciding whether or not to order a PGx test to determine a potential adverse drug reaction for an individual patient, how important are the following considerations?"

2 Survey Question: "In your opinion, when determining the value of a PGx test to identify a patient who is unlikely to respond to a drug (efficacy), how important are the following considerations?") 


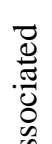

)

. $\frac{0}{0}$

के क

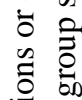

.

중

d

పัँ

을 $\frac{\frac{1}{0}}{\frac{\pi}{3}}$

3

気

岂.

정

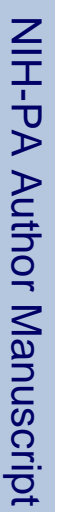

ऐ) ब

\begin{tabular}{|c|c|c|c|c|c|c|}
\hline 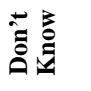 & $\begin{array}{l}\stackrel{a}{\alpha} \\
\stackrel{0}{\subseteq}\end{array}$ & 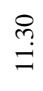 & $\underset{\mathrm{g}}{\mathrm{g}}$ & 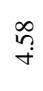 & $\begin{array}{l}\stackrel{\bullet}{\infty} \\
+\end{array}$ & $\stackrel{\text { }}{r}$ \\
\hline 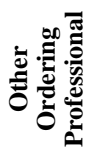 & $\underset{\substack{\mathfrak{r} \\
\dot{f}}}{2}$ & 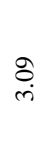 & $\underset{\underset{i}{+}}{\stackrel{+}{i}}$ & 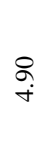 & 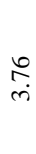 & $\begin{array}{l}\stackrel{g}{\dot{f}} \\
\dot{+}\end{array}$ \\
\hline 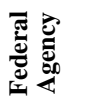 & \&̊ & $\frac{9}{6}$ & $\begin{array}{l}n \\
\sigma \\
\sigma\end{array}$ & సે & 5 & $\stackrel{\infty}{\stackrel{\infty}{\circ}}$ \\
\hline
\end{tabular}
bo능

$\infty$ 苞主

ఖ.

仓ें

०

की

号 ᄒ⿱

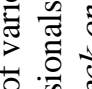

पे

要

के

调昰

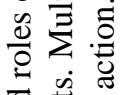

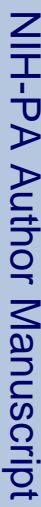

ठํ.

记

可

.

능

त्ञ

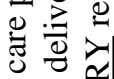

열

是言起

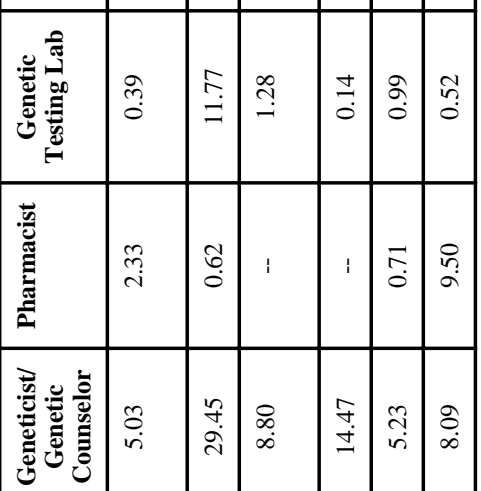

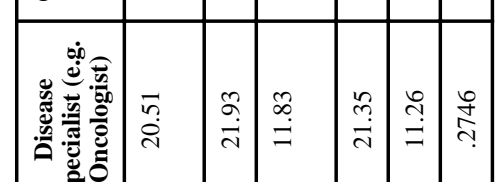

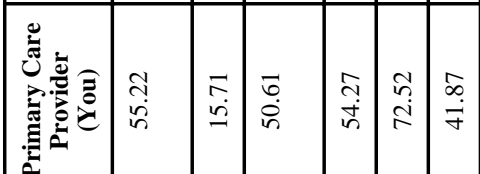

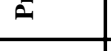

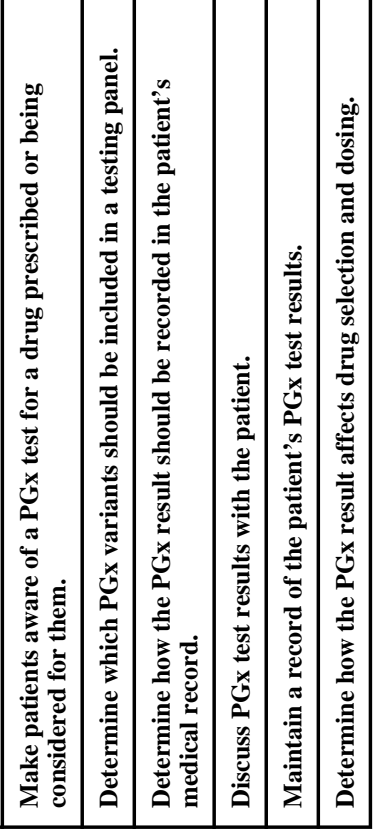

Clin Genet. Author manuscript; available in PMC 2013 October 01. 